\title{
Civic and political rights of the Batwa ethnic minority in local governance at village level: The case of Kanungu District
}

\begin{tabular}{|c|c|}
\hline \multicolumn{2}{|c|}{$\begin{array}{l}\text { Martha Kibukamusoke }{ }^{1} \text { (D) } \\
\text { Jimmy Alemiga }{ }^{2}\end{array}$} \\
\hline \multicolumn{2}{|c|}{$\begin{array}{l}\text { Affiliations: } \\
\text { }{ }^{1} \text { Department of Public } \\
\text { Administration and } \\
\text { Governance, Uganda } \\
\text { Technology and Management } \\
\text { University, Uganda }\end{array}$} \\
\hline \multicolumn{2}{|c|}{$\begin{array}{l}{ }^{2} \text { Uganda Management } \\
\text { Institute, University in } \\
\text { Kampala, Uganda }\end{array}$} \\
\hline \multicolumn{2}{|c|}{$\begin{array}{l}\text { Corresponding author: } \\
\text { Martha Kibukamusoke, } \\
\text { cfmdirector@gmail.com }\end{array}$} \\
\hline \multicolumn{2}{|c|}{$\begin{array}{l}\text { Received: } 22 \text { Apr. } 2017 \\
\text { Accepted: } 25 \text { Jan. } 2018 \\
\text { Published: } 08 \text { Mar. } 2018\end{array}$} \\
\hline \multicolumn{2}{|c|}{$\begin{array}{l}\text { How to cite this article: } \\
\text { Kibukamusoke, M. \& } \\
\text { Alemiga, J., 2018, 'Civic and } \\
\text { political rights of the Batwa } \\
\text { ethnic minority in local } \\
\text { governance at village level: } \\
\text { The case of Kanungu District', } \\
\text { Africa's Public Service } \\
\text { Delivery and Performance } \\
\text { Review 6(1), a162. https:// } \\
\text { doi.org/10.4102/apsdpr. } \\
\text { V6i1.162 }\end{array}$} \\
\hline \multicolumn{2}{|c|}{$\begin{array}{l}\text { Copyright: } \\
\text { (c) 2018. The Authors. } \\
\text { Licensee: AOSIS. This } \\
\text { is licensed under the } \\
\text { Creative Commons } \\
\text { Attribution License. }\end{array}$} \\
\hline \multicolumn{2}{|l|}{ Read online: } \\
\hline 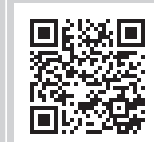 & $\begin{array}{l}\text { Scan this QR } \\
\text { code with your } \\
\text { smart phone or } \\
\text { mobile device } \\
\text { to read online. }\end{array}$ \\
\hline
\end{tabular}

Since the 1970s, the Batwa ethnic minority group has been considered as a less superior group of human beings. They were forcefully evicted from the forest around Echuya Forest Reserve in Kisoro and Kabale districts of South-Western Uganda. The Batwa in Uganda are one of the most defenceless (vulnerable), marginalised, voiceless (powerless) and endangered ethnic minority group in the districts they live in. In turn, their civic and political rights (the right to vote and the right to be voted) in local council (LC) elections have been ignored partly because of poor sensitisation to and awareness of the Batwa people by all stakeholders. The purpose of this study was to investigate the civic and political rights of the Batwa people in Uganda. The key questions to be addressed include:

1. Is the Batwa ethnic minority group aware of the right to vote in Local Council 1 elections in the communities?

2. Is the Batwa ethnic minority group aware of the right to be voted for in Local Council 1 elections in their communities?

\section{Introduction and background}

Historically, every large society contains both ethnic and linguistic minorities (Laurie \& Khan 2017). Generally, an ethnic minority is a group of people that differs from other dominant (majority) groups in terms of race or colour, nationality, religion and cultural origin in the country in which they live. Ethnic minority groups in themselves also differ based on custom, language (accent), dress, food preference, lifestyle, socio-political-economic beliefs and customs, among others, that are practised by the members of a particular group (Barzilai 2010). Globally, many minority groups based on religion, race, appearance and culture exist and are recognised, although the majority groups of people and other legal instruments tend to dominate over them in the societies in which they live, which normally absorbs them. Very few have managed to self-segregate themselves from the larger society (Laurie \& Khan 2017). Feagin (1984) gives at least five features that an ethnic minority group must have: suffering discrimination and subordination; physical and/or cultural traits that set them apart, and which are disapproved by the dominant group; a shared sense of collective identity and common burdens; socially shared rules about who belongs and who does not; and the tendency to marry within the group because of discrimination.

In many circumstances, minority people generally have been excluded politically, economically, socially and legally, among others, which has increasingly infringed their basic human rights. In addition, ethnic minority groups may be discriminated against either directly, based on a person's perceived membership of a minority group (without concern of the person's achievement), or indirectly, based on social structures that are not equally accessible to all (e.g. education, health, housing, land and employment, to mention but a few). However, there have been continuous debates since the 20th century, when the concept of ethnical minority groups gained dominance. Debates were mainly concerned with the classification of ethnic groups. In many cases, the membership of an ethical group has tended to be divided into ethnic subgroups, which may themselves be identified as independent ethnic groups, depending on the source consulted (Michael 2017).

The estimated population of the Batwa, also called Twa people (pygmies) in Rwanda, Burundi, Uganda and Eastern Congo, is between 86000 and 112 000, with other reports putting the figure at 126 000. In Uganda alone, the population of the Batwa also called the (Abayanda) is estimated to be nearly 6705 (Melanie 2015). The Batwa people mainly engage in economic activities which 
include hunting, fruit gathering and farming (Bamuturaki 2016). In Uganda, the Batwa are one of the most defenceless (vulnerable), marginalised, voiceless (powerless) and endangered ethnic minorities around the Echuya Forest Reserve in Kisoro and Kabale districts of South-Western Uganda (Minority Rights Group International 2011). Originally, the Batwa people are believed to have originated from the Ituri forest of the Democratic Republic of Congo in search of wild animals to hunt. They ended up moving into Kisoro (which can be translated as the area occupied by wild animals) and then later spread into the nearby districts (Plumptre 2004; The Republic of Uganda 2003). Their civic and political rights have been stepped on as the world watches. The Batwa people, originally based around the mountainous forest areas covering lake Kivu and Lake Edward in the Great Lakes region, have been evicted from the forests since the 1970s-1980s, hence becoming landless and losing a sense of belonging in the society. This followed legislation (in chapter 282 of the National Parks Act 1974) passed in 1974 that allowed the creation of national parks as part of a wider campaign to boost the tourism industry. This Act was adopted from the National Parks and Wildlife Act 1974 enacted by the New South Wales Parliament in Australia. This badly affected the Batwa people and their traditional lifestyle (social, economic and political), which included game hunting, fishing, fruit gathering and animal trapping, among others (Kabananukye \& Kwagala 2007).

As their lifestyle was disrupted, the Batwa people ended up becoming causal labourers commonly engaged in pottery, building works, being used as domestic workers and working on other people's farms. They also engaged in subsistence farming, making crafts and sometimes being used as a tourism attraction. The Batwa have been denied access to the basic human rights (e.g. education, health, housing and owning property/land) and have been generally excluded from exercising their civic and political rights, despite all the legal instruments such as international, regional and domestic regulations. This has largely kept the Batwa people highly illiterate and hence unaware of their rights and freedoms as humans, and they have lost their social status (Douglas \& Jaap De Visser 2015). In addition, the Batwa in Uganda have been marginalised and further made powerless; thus, their civic and political rights have been at stake. They have been neglected of the right from the lowest levels of governance (Local Council 1, or LC1), that is, elections, and hence have not been adequately represented either as voters or as candidates. Their political franchise (suffrage) in the right to vote and the right to be voted (candidate eligibility) in any election (political office) at all levels in Uganda is a great concern. The combination of the two rights is called full suffrage (Arthur 2014).

The Batwa have been denied the active right to vote because they have been made powerless or vulnerable, marginalised and exploited, as they have no access to land, education, housing and health. They are forced to live in the forests with wild animals, while sometimes being used as tourist attraction (Wairama 2001). The high levels of illiteracy and ignorance, coupled with slow government efforts to provide education, as well as less efforts put in to actively sensitise and create awareness among the Batwa about their civic and political rights, has kept them as observers in governance issues in their communities. Many times this lack of knowledge about voting has limited their access to basic education (Alexander 2000; Michael 2017; Neill 2003). In Uganda, suffrage is available to any qualifying citizen once they are at the voting age, which is 18 years, and they are sane and in sound mental health. However, the Batwa are looked at as children given their physical appearance (an adult Mutwa who is above 18 years of age is sometimes below $1 \mathrm{~m}$ height); thus, their physical appearance, civic knowledge, level of education and social class, among others, have resulted in these people being ignored in terms of their civic and political rights. Very few Batwa people exercised their right to vote during the recent national and local elections in Uganda (Douglas \& Jaap De Visser 2015).

The Batwa have limited chances of being voted to run for office (passive right to vote). This is mainly because they are landless after being evicted from the forest in 1970s; thus, they remained landless and lost their socio-economic status (SES). Some of the major frustrations the Batwa faced included lack of formal employment because of illiteracy, high levels of poverty and low or no income; these affected them, thus limiting their participation in elections as candidates. Over the years, very few Batwa have contested for an election office at even the lowest level of governance in their communities or villages (Andrea 2013).

There are many cross-cutting reasons that can explain why the Batwa people are not participating in the political process in their communities. Some of the leading factors include the lack of interest and the biased decisions made by LC courts in favour of other communities, which caused some kind of segregation among the Batwa. The Batwa have a negative perception of LCs as institutions that perpetuate their marginalisation and exploitation. The Batwa are considered primitive and backward, with no minimum requirement. The minimum requirement for someone to be eligible to contest for LC elections includes the following: one must be above 18 years of age, no academic requirement, a minimum of five registered voters in the electoral area and 20000 Ugandan shilling (i.e. about 6-7 USD). The time period a contestant is expected to ensure full registration is 30 days before nomination and three recent postcard-sized photographs (Electoral Commission 2015). However, these requirements are still way too high for many Batwa candidates whose participation has been largely restricted.

Despite the fact that the Batwa people cannot even hold their leaders accountable, the Election Commission's local government election results from 2011 indicated that there is no single councillor from the Batwa ethnic minority group in the Kabale and Kisolo district councils and yet these districts are inhabited by the Batwa ethnic minority group. Given the dominance of the other ethnic groups, it is unlikely that the Batwa people will ever have a chance to be elected, even 
at the lowest LC level (Douglas \& Jaap De Visser 2015). The United Organisation for Batwa Development in Uganda (UOBDU) has been trying to advocate and lobby for them to ensure their participation in regional and international events such as the African Commission and United Nations (UN) meetings (UOBDU 2004).

This article examines the civic and political rights (civic rights) of the Batwa in Kanungu District in Uganda. It focuses on the right of the Batwa to vote and to be voted in the political process in the communities (LC1) or village elections. The article concludes that the Batwa are treated as lesser citizens and have not been able to participate in suffrage as voters or eligible candidates because of a lack of civic knowledge, discrimination in education, health, housing, ownership of land, SES and employment, among others. This has led to marginalisation, suppression, oppression and exploitation that threaten to eradicate the Batwa completely from Uganda.

\section{Problem statement}

Despite the legal instruments in place to protect and promote the civic and political rights of the Batwa people in Uganda (the International Labour Organization - ILO [1919] Convention [169], African Commission on Human and Peoples' Rights ACHPR [1986] Article [62], and the Constitution of Uganda [1995] Articles [32 and 36], among others), marginalisation and absence of the Batwa continues in LC elections (Andrea 2013; ILO/ACHPR 2009; Kabananukye \& Kwagala 2007). The marginalisation has been because of, among others, lack of civic knowledge, discrimination in education, health, housing, ownership of land, SES and employment. This has led to marginalisation, suppression, oppression and exploitation that threaten to eradicate the Batwa completely from Uganda (Bamuturaki 2016; Douglas \& Jaap De Visser 2015; UOBDU 2004).

\section{Objectives of the study}

The study had the following objectives:

1. to find out if the Batwa ethnic minority group is aware of their right to vote in LC1 elections in their communities

2. to find out if the Batwa ethnic minority group is aware of their right to be voted for in LC1 elections in their communities.

\section{Legal instruments of civic and political rights of the Batwa people}

The Constitution of the Republic of Uganda of 1995 clearly recognised 65 ethnic communities in Uganda, including the Batwa. According to the amended Constitution of Uganda (1995): 'everything shall be done to promote a culture of cooperation, understanding, appreciation, tolerance and respect for each other's customs, traditions and beliefs'. The Constitution of the Republic of Uganda 1995 does not, however, define 'minorities', but provides under Article 36 that 'minorities have a right to participate in decision-making processes and their views and interests shall be taken into account in the making of national plans and programmes', as confirmed by Wairama (2001).

Furthermore, the Constitution recognises five fundamental rights of all Ugandans: equality and freedom from discrimination, respect for human dignity and protection from inhuman treatment, the protection of freedom of conscience and religion, the protection of minorities and the right to culture and similar rights (Douglas \& Jaap De Visser 2015). In addition, Article 32 mandates that the State take affirmative action in favour of groups that have been historically disadvantaged and discriminated. This provision, while primarily designed or envisaged to deal with the historical disadvantages of children, people with disabilities and women, is the basic legal source of affirmative action in favour of indigenous peoples in Uganda, like the Batwa ethnic minority group.

Fortunately, the Land Act of 1998 and the National Environment Statute of 1995 protect customary interests in land and traditional uses of forests. However, these laws also authorise the government to exclude human activities in any forest area by declaring it a protected forest, thus nullifying the customary land rights of indigenous peoples. It is unfortunate that Uganda has not yet ratified ILO Convention 169, which guarantees the rights of indigenous and tribal peoples in independent states. Uganda was absent in the voting on the UN Declaration on the Rights of Indigenous Peoples in 2007 (Bamuturaki 2016; Kabananukye \& Kwagala 2007).

\section{Methodology of the study}

This study was grounded on a qualitative methodology, which involved the use of oral interviews for key informants and focus group discussions (FGDs) for the community. Face to face interviews and FGDs were used to capture respondents' perceptions, expressions, opinions, beliefs, and attitudes on the subject matter. The study also used the documentary review method for collection of secondary data. Some of the secondary data included legal instruments, government reports and the Internets to supplement the primary data, so as to adequately answer the pertinent questions of the study, as supported by Harding (2013).

The study was conducted in Kinkizi County, Kayonza Subcounty in the villages of Karehe and Buhoma in Kanungu District of Uganda. The study population comprised 535 Batwa as supported by the 2001 Uganda population and housing census. The Batwa were categorised into a total of 44 focus discussion groups with each group having 12 participants. It was easy to manage, and to control any possible chaotic occurrences among the participants. With the help of an interpreter, respondents were asked openended questions during the interviews in their local language. This was done to probe and generate discussions with the participants and ease the ability to take note of key themes in form of summaries. A total of 10 interviews were carried out where three Members of Parliament, four Local Council leaders, one mayor, one town clerk and one Resident District Commissioner (RDC); these were purposively sampled. 
The sampling technique was purposive for district leaders with the main advantage of probing, while a simple random data technique was used to collect data from the Batwa ethnic minority group. The study commenced on 30 April and ended on 28 May 2017. However, some follow-up sessions were made between June and July 2017 to help authenticate the first set of data collected. The data were analysed using the Atlas ti- 8 Windows software by Microsoft for qualitative data analysis to generate statements, quotes and phrases. This was useful in making meaning from the vast array of raw data from the field.

\section{Ethical considerations}

All respondents' privacy has been respected.

\section{Findings and discussion}

Data collected from the qualitative interviews and focus group discussions were analysed and used to respond to the research objectives stated above.

\section{The right to vote by the Batwa ethnic minority group in their communities}

\section{Civic knowledge}

Civic knowledge, also called civic or voter education, is the process of educating voters about their rights and their political system for an election to be successful and democratic. It is about citizens working together to make or bring about a change in their community using the political processes. These processes are to improve the community well-being and recover public goods, among others. However, the majority of respondents agreed that they knew very little and some totally knew nothing about their civic rights. They had insufficient knowledge and information on casting their ballots and to be part of a meaningful voting process. One respondent argued:

The government has not seriously considered the Batwa as voters even if they are Ugandans. The Batwa lack information on elections, they cannot use election materials and there are no programmes and mechanisms specifically for the Batwa ethnic minority group to be able to fully participate in an election. Therefore, the Batwa lack information on who is eligible to vote, where and how to register, how voters can check the voter lists to ensure they have been duly included, what type of election are being held[sic], when, where and how to actually vote, the list of candidates and what to do before, during and after an election. (Male participant, group 3)

The respondents also cited that civic education is important because it helps to convey knowledge of the country's political processes, and provide information on the system of government and authority of the offices to be filled in as they go through the election process. Civic education conveys the significance of democracy and good governance, civic and political rights, benefits of peace, security and national development and reconciliation. In addition, the majority of respondents agreed that civic knowledge was a central aspect of promoting women's rights among the Batwa people to encourage them to participate in elections, particularly through the dissemination of positive and competitive images of women as voters, leaders and participants in all aspects of the political process in their communities.

These responses disclosed that access to civic knowledge for all citizens is not true for the Batwa. They have not been included in the pre-, during and post-election processes to equip them with their power to vote and how this vote can help them change their society for a better well-being. A comprehensive universal election coverage of the electorate among the Bawta has been very limited, and yet the majority are illiterate, disadvantaged and discriminated against in all community activities, including voting, because of overmarginalisation, oppression and suppression, among others.

The findings for this section relate to those by Prentice and Robinson (2010), who agreed that for one to have civic knowledge, one has to be able to demand a free and fair democratic process. The inclusion of women in the democratic process should be seriously considered. This is important because it can help alleviate discrimination and poverty that is faced by ethnic minority groups across the world. This therefore instils confidence in women and encourages them to participate more in the democratic process. Markus and Conner (2013) added that to be marginalised as an ethnic minority group is bad enough, but to be a part of such a group as a woman makes it even more disastrous to the process of ensuring that all people enjoy their civic and political rights. Minority groups believe that they have to vote as a family, not through the known secret ballot. This shows that they have very limited knowledge about the civic process. Family voting denies women among the minority groups the ability to vote because only the men are considered as decision makers on behalf of their families. Therefore, effective civic knowledge and education campaigns have to start early and continue through the whole election process, starting from voter registration until the casting of the ballot (McCartney, Bennion \& Simpson 2013).

Furthermore, Mossberger et al. (2007) posited that it is the responsibility of the government and specifically the body in charge of election management, to educate voters and keep them well-informed of the type of election to be held, the polling date and location, when the polling station will be open and how to cast their ballots. Voter education should be provided even on election day; there should be posters and other materials inside the polling stations, and even inside the voting booths, explaining the voting process and how to mark the ballot. This can all be done through channels like the media, among others. Civic education can also be included in the education curriculum of the country from the primary school, so that when the children are old they will know about voting process and procedures, which will enable them to participate in elections in a well-informed manner.

\section{Discrimination}

The Batwa are below average height, being less than $1 \mathrm{~m}$ of height even as adults, and thus look like small children. This natural fact has led to the Batwa being discriminated against. The majority of respondents agreed that they 
continue to suffer discrimination from the other larger ethnic groups. They further face prejudice and discrimination from the dominant society, which refers to them as 'pygmies'. This has always humiliated them and makes them feel human. Many of the Batwa participants agreed that the communities (e.g. Ryabitukuru in Kisoro District) were burned out of their homes under discrimination, which was worsened by over-marginalisation, exploitation and suppression. For example, almost $99 \%$ of the families or households were targeted in the community. This fact scared them away, and even made some homeless. The Batwa ended up being deprived of any compensation, thus forcing many to abandon their homes to hide or live in the bushes. One Mutwa confirmed:

Because of our natural physical appearance, we are discriminated against in all aspects of life, for example, education, health and elections. We are hunted down by mobs who move from house to house beating us up and destroying our property completely. This forces us to flee from our own security. We are treated as wild animals. (Male participant from focus group discussion group 8, who was seconded by two others in the same group)

\section{Another respondent reported:}

'We are used for ritual sacrifice and other traditional purposes. For example, our women are raped because it is assumed that they can heal men from witchcraft and chronic diseases like HIV/AIDS. But when it comes to financial or political gain, the Batwa are well treated, for example we are dressed in suits, dance and our pictures taken and as tourism attraction after which we are told to go back to our places'. (Still from focus group discussion groups 8 and 9 , two men agreed to this)

\section{Another added that:}

\begin{abstract}
'The Batwa who are lucky to be elected into political offices are either half Batwa or they have been assimilated fully or integrated to the larger community. We are considered very violent as wild animals that we cannot be trusted with leadership [sic]'. (Male participant from focus group discussion group 8)
\end{abstract}

The responses here show that the Batwa ethnic minority group are discriminated against and marginalisedpolitically, economically and socially. They have very little or no access to a meaningful type of education or health facilities to transform their lives as compared with other major communities, as they cannot afford such services. This is what has partly contributed to the denial of the Batwa voting rights in Uganda, as confirmed by Wairama (2001).

The above findings show that the Batwa people face more discrimination than any other minority groups in Uganda. They suffered from violence and discrimination and this has had many negative impacts, thus destroying their community through rendering them homeless, over-marginalised, exploited and supressed, and making them targets for ritual sacrifice. There is also a popular perception of the Batwa as barbaric, savage, wild, uncivilised, ignorant and unclean, which contributes greatly to their discrimination and exclusion from mainstream society.
These findings are similar to that of Melanie (2015), who agreed that very few people actually understand the concept of respect for human beings and non-discrimination against others, irrespective of status in society. The Batwa are discriminated against as ethnic minority groups because of poor social support structures that are instrumental for those with very limited political access and participation. This is supported by the fact that the community and the Batwa themselves lack adequate sensitisation and are thus not treated as Ugandan citizens who enjoy full rights under the Constitution of the country. There is a clear-cut lack of coordination of efforts to assist the Batwa, and a serious scarcity of information in the form of literature or data relating to the Batwa, who are often treated as a peripheral part of the communities in which they live (Minority Rights Group International 2011).

\section{Education}

The majority of respondents agreed that most of the Batwa are not educated because they cannot afford to take their children to school. This is because of poverty-related circumstances, stigma and lack of scholastic material, despite the fact that the government has provided free universal primary education (UPE). The majority of the Batwa do not speak English and yet it is used as a medium of teaching in school. This scares the Batwa from enrolling in school. The kind of education the Batwa want for their people is expected to involve teaching and promoting of their cultural norms and traditions; otherwise, many would continue to drop out of school. Four Batwa parents confirmed:

'The syllabus of the children does not teach how to preserve culture. I cannot take my children to school because they do not teach about the preservation of our culture but instead children are taught how to destroy their own culture.'(Four parents from focus group discussion group 7)

However, some Batwa agreed that even if they have never attended any form of education, they were happy that their children had been taken to school by non-governmental organisations, community-based organisations and wellwishers. But others added that the enrolment rates are still very low because the Batwa live in hard-to-reach and therefore hard-to-teach areas that are far from schools.

The above findings show that although the Government of Uganda (GoU) provides for free education, there were very few enrolled students, especially from the ethnic minority groups like the Batwa. Thus, the lack of education is one strong factor that explains the continued marginalisation of the Batwa as a community, and educating their youth and children is one way of empowering them and also ensuring the quality development of their community as reported by the UOBDU (2011) report.

Wairama (2001) argued that the 1995 Constitution guarantees the right to education under Article 30. Article 34 requires the state and parents to offer basic education to a child. It also accords special protection to orphans and other vulnerable children. The UPE, introduced in 1997, aimed at enrolling all 
school-going children in Uganda, but has faced many challenges, such as poor management, that have adverse effects on the minority groups as supported by UOBDU (2004).

\section{The right of the Batwa to be voted to represent others}

\section{Employment}

Employment can be generally defined as a relationship between two parties (employer and employee), normally based on a contract in which work is paid after a specific period of time (daily, weekly, monthly, bi-annually or annually) governed by employment laws. The employees work in return for pay depending on the type of work, and in some cases accumulation of other benefits like health insurance and allowances is emphasised (Budd \& Bhave 2010). The majority of respondents reported that most of the Batwa people have no formal employment but are employed informally by others or self-employed at very domestic levels; hence, they are facing much financial difficulty. They further added that the Batwa people have suffered psychological and emotional pain because they cannot afford money to sustain them through an election process, for example, registration, campaigns printing posters and paying for agents or election petitions in cases of grievances.

The respondents also agreed that the Batwa people seem to have lost their social dignity simply because they have lost identity, and suffer discrimination when applying for employment, at health centres and in their communities, which suppresses their civic and political rights, not allowing people to look at them as legitimate candidates for any political office. One respondent stated:

\begin{abstract}
'No matter how much we the Batwa try to get formal employment in both government and private sectors, no matter how strong or qualified we are, no matter how much we try our best to persuade them we lose out on the employment opportunities due to poor education and experience. This has gone on for years without any redress, hence making us loose [sic] self-confidence and esteem. Then how then do you tell us to contest for a political office in such a community which discriminates [against] us?' (Male participant from focus group discussion group 8)
\end{abstract}

Other respondents blamed lack of formal employment of the Batwa people on the poor government policies on employment of the ethnic minority groups. Lack of formal education as another factor has kept the Batwa in constant poverty because of lack of employment. As a form of survival, the Batwa are informally employed in substance agriculture, hunting and fruit gathering and are sometimes used as tourism attraction for free or for very little pay.

The responses discussed above show that the Batwa suffer high rates of unemployment and face more obstacles to engage in informal work, and thus receive lower pay than other majority groups. The Batwa women face the unemployment problem more because they are more vulnerable and some are single mothers with little or no skills at all to employ in any work. With this kind of incapacity, the Batwa are not in a good position to vie for any political office in their communities.
In a study conducted by Kevin (2015), it was noted that ethnic minority groups in any community suffer unemployment, which reduces their chances of owning land, actively participating in and feeling part of the community. Studies concluded by Archer (2014) and Anderson (2017) confirmed that there is a considerable weakness that ethnic minority groups face in terms of securing employment. Their physical appearance alone reduces their chances of getting jobs that may not need an education level, for example, office cleaning, office messengers and tea persons, among others, as suggested and supported by Budd and Bhave (2008).

Baert (2016) suggested that it is not until ethnic minority groups achieve full employment by addressing factors that prevent them from being competitive and having equal opportunities for jobs at all levels, that equality will be realised. Acocella (2007) added that full employment can be attained through setting the right socio-economic conditions that spur and favour all citizens, regardless of their status. this can be made possible through partnering with the government, non-governmental and community-based organisations to provide employment to everyone as a matter of human rights, which will in turn promote equal and fair civic and political rights for all humans (Befort \& Budd 2009. Wolff 2012).

\section{Landlessness}

The majority of respondents stated that the Batwa people were evicted from the Mgahinga and Bwindi forests, which negatively disrupted their traditional forest-based lifestyle. This lifestyle included the economic activities of hunting and gathering from the forest. However, others added that few Batwa still live in the forest but are trailed and sometimes killed if found there. Most of the Batwa live on the periphery of their ancestral forest lands. This landlessness has forced the Batwa to lack a sense of belonging within the society, stifling the ability to represent or to be represented in any political process. One Mutwa added:

'It is very difficult for us to get elected into any political office even at village levels because we are landless and have no people to vote us into any office. Many of the Batwa people have abandoned their heritages and this has become very difficult for a Mutwa to win. We have now become squatters on the lands of our neighbours'. (Male participant from focus group discussion group 7)

\section{Another Mutwa said:}

'The land we were evicted from is our customary land and our forefathers were born here. But now we are being marginalised and oppressed on our own land simply because it has been converted into game parks and game reserves without provision of alternative means of our livelihood and cultural considerations'. (Male participant from focus group discussion group 7)

Although the Batwa pointed out that land leases were available to them, they were worried about what will happen when the leases expire. They added that this is coupled with a situation where some Batwa are being treated as squatters. Even the court cases the Batwa have filed have not returned 
their customary land. The Batwa submitted a petition to the Constitutional Court of Uganda in February 2013, seeking recognition of their status as indigenous people under international law. They needed redress for the historic marginalisation and continuous human rights violations they have faced as a result of being dispossessed of their ancestral forest lands by the government, but nothing has yet been realised. As a result, the Batwa have seen the heart of their culture, traditions, beliefs and wealth swept away. They have become squatters on other peoples' land and have less chances of being elected into any political office as they are treated as landless.

The above findings show that the Batwa were evicted from their land without any alternatives, thus contributing greatly to the destruction of their cultural heritage, which they held in very high esteem. Their land was converted into game parks and forest reserve so as to attract tourists to boost the country's foreign exchange in places such as Bwindi and Mgahinga, yet they have not benefited from such revenue collections. Worse still, the court case filed by the UOBDU has since been withdrawn as a result of a collaborative agreement with the Uganda Wildlife Authority; this has perpetuated more violence.

This finding is in line with that of Andrea (2013) and Douglas and Jaap De Visser (2015), who reported that the Batwa lost land to the government for purposes of tourism and revenue collection, leaving them as squatters. They risk losing their livelihoods and being eradicated if they are not given an immediate alternative to own land and re-form their once prestigious community. If a permanent solution is not reached for the Batwa people, they will be assimilated or absorbed into the larger or dominate society as a result of modernisation. They have not been offered any meaningful protection during this transition of displacing them from their customary land.

According to Kabananukye and Kwagala (2007), it was wrong for the Batwa to be evicted from the forests because they have certain spiritual and religious ties with forests. Specific sites are revered and considered central to their existence, thus move through the past and present through sacrifices and sacred places. Each geographical area, especially those inside forests, has a name that relates to history and the remote past also called the world of mythical ancestors. Therefore, evicting the Batwa from their own land is a great loss to the common heritage of humankind. They added that the Batwa are already a small ethnic minority; hence, this drastic change to their lifestyle has brought the Ugandan Batwa close to extinction.

According to Andrea (2013), the Batwa people have found it hard to maintain their right to land and to claim compensation from the loss of their land given the fact that their customary rights to land are neither expressly protected in written law nor recognised in the customary land rights system in Uganda. As a result, the Batwa have seen the heart of their culture, traditions, beliefs and wealth swept away. They have also lost a sense of belonging, as reported by ILO/ACHPR (2009).

\section{Socio-economic status}

Socio-economic status is a total measure of a person's work experience that includes an individual's or a family's economic and social position based on the level of income, education and employment. SES is categorised into three classes: low, middle and high classes (Williams 2010). The majority of respondents reported that the Batwa people typically fall in the low class and because of this they are not eligible to be voted into any political position.

Furthermore, it was noted that the Batwa are sickly and illiterate people, engulfed in high forms of poverty which limit them from financially affording to join political campaigns. They cannot even afford basic needs like food, shelter, medicine, safety, clothes and education. The best a Mutwa can get as employment is working on people's farms as labourers, with many engaged in subsistence farming deep in the forests away from the towns that they know little or nothing about. This results in little or no access to civic and political rights education.

The above responses prove that the SES class of any person can easily affect the feeling of belonging of any community. This explains why the Batwa have been evicted from their customary land and ended up as squatters, given their low level of education, income and employment. This has made them less empowered in the communities in which they live and they are thus treated as strangers.

According to Markus and Conner (2013), the level of SES class can define who we are in any community. Unless ethnic minority groups like the Batwa people are given full access to education, other social benefits and basic needs (e.g. food, shelter, medicine, safety, clothes and education), they will remain marginalised, exploited, suppressed and oppressed.

Williams and Mohammed (2013) confirmed that ethnic minority groups lack eligibility to stand for any political office based on the fact that their income, financial security and general opinions of their social status and social class work against them in contesting and winning an election. SES has become a constant and reliable predictor of many life outcomes, ranging from political to economic and social outcomes, among others. It further affects the mental and physical health of those who have faced it over time and have no ability to change their status for the better. This can be one of the major causes of disparities and inequalities that exist in every society today.

\section{Conclusions and recommendations Conclusion}

The study concluded that the Batwa ethnic minority group are treated as lesser citizens in comparison to other groups and have not been able to participate in suffrage, either as 
voters or as eligible candidates. The reason for their inability to participate stems from their lack of civic knowledge, discrimination in terms of education status, health, housing, ownership of land, SES and employment, among others. This has led to marginalisation, suppression, oppression and exploitation that eventually threaten to eradicate the Batwa completely from Uganda.

\section{Recommendation}

\section{The right to vote}

Civic knowledge: The GoU must develop and disseminate a comprehensive and all-inclusive programme to all eligible voters, including the ethnic minority groups like the Batwa people. This would be to educate them about their civic and political rights through civic education. This kind of civic knowledge must be passed on to all voters (women, men, minority groups, youth and others) well before each election. This must continue throughout the election process and post-election process to avoid violent conflicts and riots because of voter dissatisfactions. In addition, family voting must be discouraged and banned because it violates the civic and political rights of the Batwa.

Discrimination: The GoU must ensure that it strongly implements the political will and introduces more realistic policies that combat discrimination and at the same time promote and protect the ethnic minority groups at the very highest levels of government. This will help and clearly stipulate that discrimination be regarded as unacceptable and criminal in Uganda. Such policies must be provided to all through trainings and sensitisation workshops. These workshops should attract and include all members of minority groups at all stages and in turn help to promote civic and political rights.

Education: Although the GoU adopted the UPE policy where education for all is a must, it should ensure a better or more functional education programme that includes and provides an all-inclusive intercultural educational curriculum that has a mixture of theory and practice or mixed with vocational training for all groups of Ugandans across the social strata. This type of education entails teaching citizens about the democratic and good governance processes including civic and political rights to empower the ethnic minority to become eligible to be voted into political structures, thus enhancing democratic principles.

\section{The right to be voted and eligibility of candidates}

Employment: The GoU must ensure that it drafts and implements policies aimed at achieving full employment for all groups and classes of people across the social strata. This will help all groups of people to have an equal chance of securing a quality job, whether they live in towns, rural or forest areas. This includes the Batwa ethnic minority group.
It is hoped that the policies will be able to effect positive change on the social, economic and political conditions of the minorities. This will attract the interest of the Batwa people and encourage them to actively practise their civic and political rights.

Landlessness: The GoU should be in a position to enact land laws or enforce the existing ones like the Land Act of 1998 and the National Environment Statute of 1995 that aim at protecting customary interests in land and traditional uses of forests. This will help in supporting the Batwa as indigenous people to own their customary land through a mailo or freehold title and remove the mentality of them thinking that if they get land leases, they may expire and leave the Batwa landless or as squatters. This will eventually encourage them to participate actively in the political processes as landlords.

Socio-economic status: The GoU must ensure that education, financial security and other basic rights are afforded freely to the people, regardless of class. They should be provided at no cost to avert inequality at all levels, in order to reduce the gaps in the SES of the country. This will promote socio-economic development, and hence improve the quality of life of the many people in the low economic class, and will eventually reduce the psychological torture faced in society. This will boost the morale of all citizens to participate in civic and political rights freely, willingly and without any class intimidations.

\section{Acknowledgements Competing interests}

The authors declare that they have no financial or personal relationships which may have inappropriately influenced them in writing this article.

\section{Authors' contributions}

M.K. who was the team leader worked with J.A. to ensure the article was developed. J.A. was responsible for developing the literature review which formed the basis from which the gap was identified. Using a sample which was derived from a given population, M.K. collected and analysed the data from which the report was developed.

\section{References}

Acocella, N., 2007, Social pacts, employment and growth: A reappraisal of Ezio Tarantelli's thought, Springer Verlag, Heidelberg.

Alexander, K., 2000, The right to vote: The contested history of democracy in the United States, Basic Books, New York.

Anderson, E., 2017, Private government: How employers rule our lives (and why we don't talk about it), Princeton University Press, Princeton, NJ.

Andrea, M.P., 2013, The forgotten's advocate, Centre for Batwa Minorities, viewed 08 February 2018, from https://cfmuganda.word press.com/2013/08/30/the-forgottensadvocate/

Archer, R., 2014, A management guide, 4th edn., Cengage Learning Australia, South Melbourne, Victoria. 
Baert, S., 2016, 'Getting grey hairs in the labour market: An alternative experiment on age discrimination', Journal of Economic Psychology 57, 86-101. https://doi. org/10.1016/j.joep.2016.10.002

Bamuturaki, M., 2016, Uganda: Minority groups struggle for land, representation, The Daily Monitor, viewed 16 May 2016, from http://www.monitor.co.ug/artsculture/ Reviews/Minority-groups-struggle-land-representation/691232-3204492qydgqh/index.html

Barzilai, G., 2010, Communities and law: Politics and cultures of legal identities, University of Michigan Press, Ann Arbor, MI.

Befort, S.F. \& Budd, J.W., 2009, Invisible hands, invisible objectives: Bringing workplace law and public policy into focus, Stanford University Press, Tamworth, New South Wales, Australia.

Budd, J.W. \& Bhave, D., 2008, 'Values, ideologies, and frames of reference in industrial relations', in Sage handbook of industrial relations, Sage Publications, Southern California, United States of America.

Budd, J.W. \& Bhave, D., 2010, 'The employment relationship', in Sage handbook of human resource management, Sage Publications, Thousand Oaks, CA.

Douglas, K.S. \& Jaap De Visser, 2015, 'The unresolved ethnic question in Uganda's district councils', Law, Democracy and Development 19, viewed 08 February 2018 , from http://www.theeastafrican.co.ke/news/Uganda-minority-tribes-fight-fortheir-rights-/2558-3158830-4e637ez/index.html

Electoral Commission, 2015, Basic requirements for nomination as a candidate for the 2015-2016 general elections, viewed 08 February 2018, from http://www.ec. $2015-2016$ general elections, viewed 08 February 2018, from http://wwW.ec.
or.ug/?q=content/basic-requirements-nomination-candidate-2015-2016or.ug/?q=content/
general-elections

Feagin, J.R., 1984, Racial and ethnic relations, 2nd edn., Prentice-Hall, Upper Saddle River, N.J.

ILO/ACHPR, 2009, Uganda: Constitutional, legislative and administrative provisions concerning indigenous peoples, International Labour Office, Geneva, Switzerland.

Kabananukye, K. \& Kwagala, D., 2007, Culture, minorities and linguistic rights in Uganda: The case of Batwa and the IK, Human Rights and Peace Centre (HURIPEC) Working Paper 11, Indigenous Policy Journal, Makerere University, Kampala, Uganda.

Kevin, R., 2015, Ethnic minorities' face higher barriers in jobs market, viewed 04 February 2018, from https://www.theguardian.com/world/2015/dec/28/ethnicminority-people-face-higher-barriers-in-jobs-market

Krejcie, R.V. \& Morgan. D.W, 1970, 'Determining sample size for research activities', Educational and Psychological Measurement 30, 607-610, viewed 04 February 2018 from https://home.kku.ac.th/sompong/guest_speaker/KrejcieandMorgan_article.pdf

Laurie, T. \& Khan, R., 2017, 'The concept of minority for the study of culture', Continuum: Journal for Media and Cultural Studies 31(1), 2-4. https://doi.org/ 10.1080/10304312.2016.1264110

Markus, H. \& Conner, A., 2013, Clash: 8 cultural conflicts that make us who we are, Hudson Street Press, New York, NY.
McCartney, A., Bennion, E. \& Simpson, D., 2013, Teaching civic engagement: From student to active citizen, American Political Science Association, Washington, DC p. xiv.

Melanie, G., 2015, The real pygmies experience: Evicted Batwa people now just act out a previous life for tourists, viewed 04 February 2018, from https://news.vice.com/ article/the-real-pygmies-experience-evicted-batwa-people-now-just-act-out-aprevious-life-for-tourists

Michael, H., 2017, Racial harmony is achievable: Lessons from the Kingdom of Hawaii, Palgrave Macmillan, London, United Kingdom.

Minority Rights Group International (MRG), 2011, Land, livelihoods and identities; intercommunity conflicts in East Africa, p. 6, viewed 04 February 2018, from http://www.minorityrights.org/download.php?id=1076

Mossberger, K., 2007, Digital citizenship: The Internet, society, and participation, MIT Press, Cambridge, MA

Neill, A., 2003, Adventures in democracy: A history of the vote in New Zealand, University of Otago Press, Dunedin, New Zealand.

Plumptre, A.J., 2004, 'The socio-economic status of people living near protected areas in the Central Albertine Rift', Albertine Rift Technical Reports 4, 127.

Prentice, M. \& Robinson, G., 2010, Linking service learning and civic engagement in community college students, American Association of Community Colleges, Washington, DC

The Republic of Uganda, 2003, Guidelines for collaborative forest management in Uganda, Government of Uganda, Archives.

Uganda Legal Information Institute, 1995, Constitution of the Republic of Uganda, Uganda.

Uganda Legal Information Institute, 1998, Land Act Chapter 227, Constitution of the Republic of Uganda, Uganda.

Uganda Wildlife Authority, 1974, National Parks Act Chapter 282, Uganda.

United Organization for Batwa Development in Uganda (UOBDU), 2004, Report about Batwa data, Uganda, p. 3, United Organisation for Batwa Development in Uganda, Kisoro, Uganda.

United Organization for Batwa Development in Uganda (UOBDU), 2011, Annual Report, Kisoro, Uganda.

Wairama, G.B., 2001, Uganda: The marginalization of minorities, Minority Rights Group International, Ggaba Road, Kampala, Uganda.

Williams, D.R., 2010, 'Race, socioeconomic status and health: Complexities, ongoing challenges and research opportunities', Annals of the New York Academy of Sciences 1186, 69-101. https://doi.org/10.1111/j.1749-6632.2009.05339.x

Williams, D.R. \& Mohammed, S.A., 2013, 'Racism and health I: Pathways and scientific evidence', American Behavioral Scientist 57, 1152-1173. https://doi.org/10.1177/ 0002764213487340

Wolff, R.D., 2012, Democracy at work: A cure for capitalism, Haymarket Books, Chicago, IL. 